\title{
FAKTOR-FAKTOR YANG MEMPENGARUHI ORANG TUA DALAM PENGAMBILAN KEPUTUSAN MEMILIH SEKOLAH DASAR SWASTA (SD Virgo Maria 2 dan SDIP. H. Soebandi Kecamatan Bawen Kabupaten Semarang)
}

\author{
Nurul Khasanah \\ Program Pascasarjana Magister Manajemen Pendidikan \\ FKIP Universitas Kristen Satya Wacana
}

\begin{abstract}
ABSTRAK
Penelitian ini bertujuan untuk mengetahui dan menganalisis pengaruh faktor fasilitas sekolah, budaya sekolah, lokasi sekolah, pendidikan SD berbasis keagamaan (religiusitas), dan kepuasan pelanggan terhadap pengambilan keputusan orang tua dalam memilih sekolah bagi putra-putrinya di SD Virgo Maria 2 dan SDIP. H. Soebandi Kecamatan Bawen Kabupaten Semarang yang secara keseluruhan berjumlah 818 siswa. Data dalam penelitian ini dikumpulkan dengan metode kuesioner, yang disebarkan kepada 154 responden yaitu orang tua siswa kelas I di SD Virgo Maria 2 dan SDIP. H. Soebandi Kecamatan Bawen Kabupaten Semarang.

Sampel dipilih dengan menggunakan teknik purposive sampling. Data hasil penelitian dianalisis dengan menggunakan teknik analisis regresi dengan metode stepwise dan menggunakan bantuan program SPSS Versi 20.0 for windows. Hasil penelitian menunjukkan bahwa (1) ada pengaruh positif yang signifikan antara lokasi sekolah, kepuasan pelanggan dan budaya sekolah terhadap pengambilan keputusan memilih sekolah, (2) faktor yang dominan dalam mempengaruhi pengambilan keputusan memilih sekolah adalah faktor lokasi sekolah yang berpengaruh sebesar 66,8 persen.
\end{abstract}

Kata kunci : pengambilan keputusan memilih sekolah, lokasi sekolah, kepuasan pelanggan, budaya sekolah, fasilitas sekolah, religiusitas.

\section{PENDAHULUAN}

Mendidik anak merupakan tugas yang paling mulia yang diamanatkan Tuhan kepada para orang tua. Oleh sebab itu, tanggung jawab dalam mendidik anak terletak di atas bahu orang tua. Melalui pendidikan, orang tua dapat memberikan pengaruh dalam pembentukan pribadi anak dan watak yang akan dibawa hingga dewasa. Pilihan sekolah yang tepat akan sangat membantu memaksimalkan perkembangan kecerdasan anak. Sekolah bukan hanya sebagai tempat anak mencari ilmu, namun lebih dari itu, sekolah menjadi tempat pembentukan karakter dan kepribadian si anak. Jadi, orang tua jelas harus memilih sekolah yang terbaik untuk anak. Terbaik bukan berarti yang termahal. Terbaik adalah yang sesuai dengan kebutuhan anak.

Tujuan yang hendak dicapai dalam penelitian ini adalah untuk mengetahui dan menganalisis faktor-faktor yang berpengaruh terhadap pengambilan keputusan orang tua dalam pemilihan SD Virgo Maria 2 dan SDIP. H. Soebandi bagi anaknya.

\section{TELAAH PUSTAKA}

\section{Pengambilan Keputusan Memilih Sekolah}

Pengambilan keputusan merupakan aktivitas yang disadari dilakukan manusia setiap hari. Namun berapa kali dalam sehari mengambil keputusan, orang mungkin tidak menyadarinya. Dalam kehidupan sehari-hari manusia dihadapkan pada berbagai pilihan hidup. Manusia harus memilih satu di antara pilihan tersebut yang dianggap paling baik. Proses dalam menentukan pilihan yang 
dianggap paling baik dinamakan pengambilan keputusan. Pengambilan keputusan dalam memilih sekolah merupakan suatu tindakan untuk menentukan sebuah pilihan sekolah yang dianggap paling baik oleh individu (orang tua) dengan mengacu pada tiga tahap proses memilih, menentukan pilihan, dan mengambil keputusan.

\section{Fasilitas Sekolah}

Menurut Daradjat dalam Arianto Sam (2008) fasilitas adalah segala sesuatu yang dapat mempermudah upaya dan memperlancar kerja dalam rangka mencapai suatu tujuan. Sedangkan menurut Arikunto dalam Arianto Sam (2008) juga mengemukakan bahwa fasilitas dapat diartikan sebagai segala sesuatu yang dapat mempermudah dan memperlancar pelaksanaan segala sesuatu usaha. Fasilitas sekolah merupakan segala sesuatu yang dipakai untuk memperlancar proses belajar mengajar. Adapun fasilitas meliputi: lahan tempat dimana sekolah didirikan, bangunan atau gedung sekolah, dan perabotan dan perlengkapan yang memadai untuk proses pembelajaran.

\section{Budaya Sekolah}

Istilah budaya dapat diartikan sebagai totalitas pola perilaku, kesenian, kepercayaan, kelembagaan, dan semua produk lain dari karya dan pemikiran manusia yang mencirikan kondisi suatu masyarakat atau penduduk yang ditransmisikan bersama. Budaya sekolah adalah tatanan nilai yang telah dirumuskan dengan baik dan berusaha diwujudkan dalam berbagai perilaku keseharian melalui proses interaksi efektif yang meliputi: budaya mutu, budaya belajar, dan budaya sekolah sehat.

\section{Lokasi Sekolah}

Menurut Tarigan (2006) teori lokasi adalah ilmu yang menyelidiki tata ruang (spatial order) kegiatan ekonomi, atau ilmu yang menyelidiki alokasi geografis dari sumber-sumber potensial, serta hubungannya dengan atau pengaruhnya terhadap keberadaan berbagai macam usaha/kegiatan lain baik ekonomi maupun sosial. Lokasi sekolah adalah lokasi dimana sekolah itu berada, lokasi sekolah meliputi: jarak dari rumah ke sekolah, sarana transportasi yang tersedia maupun lingkungan sekitar yang aman dan nyaman.

\section{Pendidikan Sekolah Dasar Berbasis Keagamaan (Religiusitas)}

Religiusitas merupakan aspek yang telah dihayati oleh individu di dalam hati, getaran hati nurani pribadi dan sikap personal (Mangunwijaya, 1986). Pendidikan sekolah dasar yang berbasis keagamaan (religiusitas) adalah suatu pendidikan sekolah dasar yang menggunakan kurikulum sekolah dasar namun berbasis pada keagamaan yang meliputi: pendidikan keimanan (IMTAQ), pendidikan akhlak (budi pekerti), dan pendidikan akal (IPTEK).

\section{Kepuasan Pelanggan}

Kepuasan pelanggan adalah suatu keadaan dimana keinginan, harapan dan kebutuhan pelanggan terpenuhi. Suatu pelayanan dinilai memuaskan bila pelayanan tersebut dapat memenuhi kebutuhan dan harapan pelanggan. Kepuasan pelanggan adalah suatu harapan dan kebutuhan pelanggan terpebuhi dengan mengacu pada: hasil yang dicapai, evaluasi hasil yang dicapai, dan pengembangan hasil yang dicapai. 


\section{Sekolah Dasar Swasta}

Pendidikan merupakan setiap proses di mana seseorang memperoleh pengetahuan (knowledge acqui-sition), mengembangkan kemampuan/keterampilan (skills developments) sikap atau mengubah sikap (attitute change). Pendidikan adalah usaha sadar dan terencana untuk mewujudkan suasana belajar dan proses pembelajaran agar peserta didik secara aktif mengembangkan potensi dirinya untuk memiliki kekuatan spiritual keagamaan, pengendalian diri, kepribadian, kecerdasan, akhlak mulia, serta keterampilan yang diperlukan dirinya dan masyarakat. Sekolah dasar swasta adalah sekolah yang diselenggarakan oleh non-pemerintah/swasta, penyelenggara berupa badan/ pribadi atau yayasan pendidikan.

\section{METODE PENELITIAN}

Menurut Sugiyono (2002) bahwa research atau penelitian merupakan sarana fundamental untuk memahami kesulitan dan menemukan penyelesaian bagi suatu masalah secara ilmiah atau dengan perkataan lain, penelitian merupakan penyelidikan dan pengujian yang amat kritis dan teliti secara cermat guna memecahkan masalah. Sedangkan rancangan penelitian adalah seluruh proses perencanaan dan pelaksanaan suatu riset yang meliputi kegiatan-kegiatan identifikasi masalah, rumusan masalah, pembuatan konsep/definisi, metode sampling dan teknik pengumpulan data, editing/coding dan processing data, metode analisis data, dan laporan penelitian (Supranto, 1986).

Pada penelitian ini, peneliti menggunakan jenis penelitian kuantitatif dengan rancangan non eksperimen. Penelitian yang dilakukan sesudah perbedaan-perbedaan dalam variabel bebas yang terjadi karena perkembangan kejadian secara alami disebut penelitian ex post facto (Arikunto, 2010). Untuk menganalisis apakah ada pengaruh antara fasilitas sekolah, budaya sekolah, lokasi sekolah, pendidikan SD berbasis keagamaan, dan kepuasan pelanggan terhadap pengambilan keputusan memilih sekolah, menggunakan analisis regresi berganda (multiple regression analysis). Waryanto dan Millafati (2006) mengemukakan bahwa Jika data yang akan dianalisis berskala ordinal, maka perlu ditransformasi terlebih dulu menjadi skala interval agar dapat digunakan untuk analisis lebih lanjut. Pada penelitian ini, untuk mentransformasikan data menggunakan skala Likert.

Sebelum dilakukan analisis regresi lebih lanjut diperlukan uji prasyarat analisis untuk mengetahui apakah analisis data untuk pengujian hipotesis dapat dilanjutkan atau tidak. Adapun persyaratan tersebut harus memenuhi beberapa asumsi atau prasyarat analisis, antara lain data berdistribusi normal (uji normalitas) dilakukan dengan menggunakan pengujian normal probability plot. Dalam normal probability plot setiap nilai data yang diamati dipasangkan dengan nilai harapannya (expected value) dari distribusi normal. Jika data berasal dari suatu populasi yang terdistribusi normal, maka titik-titik nilai data akan terletak kurang lebih dalam satu garis lurus pada sumbu diagonal dari grafik. Uji Heteroskesdastisitas, bertujuan untuk meng-uji apakah dalam sebuah model regresi terjadi ketidaksamaan varian dari satu pengamatan ke pengamatan yang lain (Ghozali, 2011). Uji multikolinearitas bertujuan untuk menguji apakah model regresi ditemukan adanya korelasi antar variabel bebas (independen). Model regresi yang baik seharusnya tidak terjadi korelasi diantara variabel (Ghozali, 2011). Salah satu syarat yang harus dipenuhi oleh model regresi adalah tidak ada autokorelasi. Jika terjadi autokorelasi maka kosekuensinya adalah estimator masih tidak efisien, oleh karena itu interval keyakinan menjadi lebar. Konsekuensi lain jika permasalahan autokorelasi dibiarkan maka varian kesalahan pengganggu menjadi underestimate, yang pada akhirnya penggunaan uji $\mathrm{t}$ dan uji $\mathrm{F}$ tidak lagi bisa digunakan. Untuk mendeteksi adanya autokorelasi adalah dari besaran Durbin Watson. 
Dalam upaya menjawab permasalahan dalam penelitian ini maka digunakan analisis regresi linear berganda (Multiple Regression) dengan metode stepwise. Uji Signifikan Parameter Individual (Uji t), pada dasarnya menunjukkan seberapa jauh pengaruh satu variabel independen secara individual dalam menerangkan variasi variabel independen (Ghozali, 2011). Uji Signifikansi Simultan (Uji F), digunakan untuk menguji hipotesis nol bahwa koefisien determinasi majemuk dalam populasi, $\mathrm{R}^{2}$, sama dengan nol. Uji signifikansi meliputi pengujian signifikansi persamaan regresi secara keseluruhan serta koefisien regresi parsial spesifik. Uji keseluruhan dapat dilakukan dengan menggunakan statistik $F$. Koefisien Determinasi $\left(\mathrm{R}^{2}\right)$, pada intinya mengukur seberapa jauh kemampuan model dalam menerangkan variasi variabel independen.

Analisis regresi pada penelitian ini memanfaatkan jasa komputer dengan program SPSS versi 20.0 pada MS Windows7.

\section{HASIL PENELITIAN DAN PEMBAHASAN}

Untuk menganalisis apakah ada pengaruh antara fasilitas sekolah, budaya sekolah, lokasi sekolah, pendidikan SD berbasis keagamaan, dan kepuasan pelanggan terhadap pengambilan keputusan memilih sekolah, menggunakan analisis regresi berganda (multiple regression analysis). Sebelum dilakukan analisis regresi lebih lanjut diperlukan uji prasyarat analisis untuk mengetahui apakah analisis data untuk pengujian hipotesis dapat dilanjutkan atau tidak. Adapun persyaratan tersebut harus memenuhi beberapa asumsi atau prasyarat analisis, antara lain data berdistribusi normal (uji normalitas) dilakukan dengan menggunakan pengujian normal probability plot. Dari Grafik 4.1 di atas, terlihat titik-titik menyebar di sekitar garis diagonal, serta penyebaranya mengikuti arah garis diagonal. Maka model regresi memenuhi asumsi normalitas atau layak dipakai untuk prediksi Pengambilan keputusan memilih sekolah berdasar masukan variabel independennya.

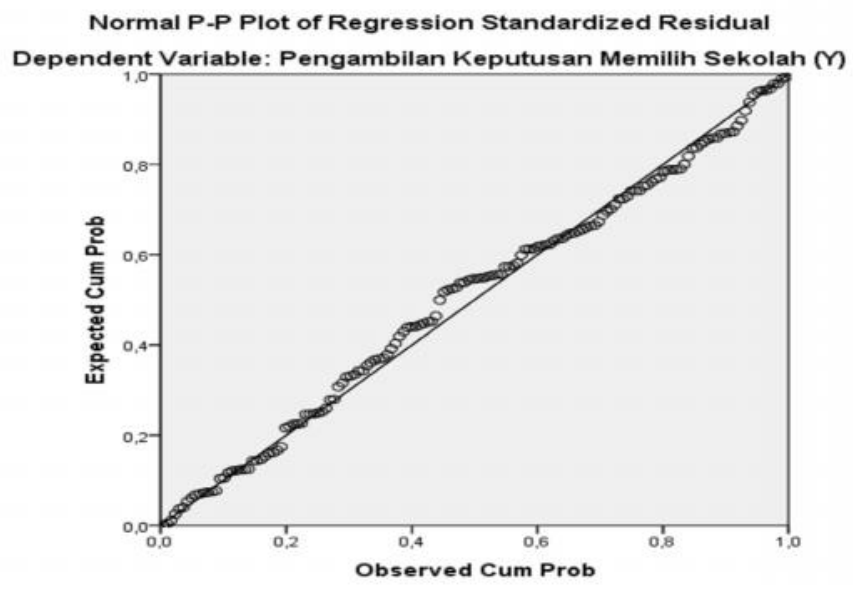

Grafik 1. Grafik Normality Plot

Uji Heteroskesdastisitas, bertujuan untuk menguji apakah dalam sebuah model regresi terjadi ketidaksamaan varian dari satu pengamatan ke pengamatan yang lain (Ghozali, 2011). Hasil pengujian heteroskedastisitas menunjukkan bahwa titik-titik tidak membentuk pola tertentu atau tidak ada pola yang jelas serta titik-titik menyebar di atas dan di bawah angka 0 (nol) pada sumbu Y, maka tidak terjadi heteroskedastisitas. 


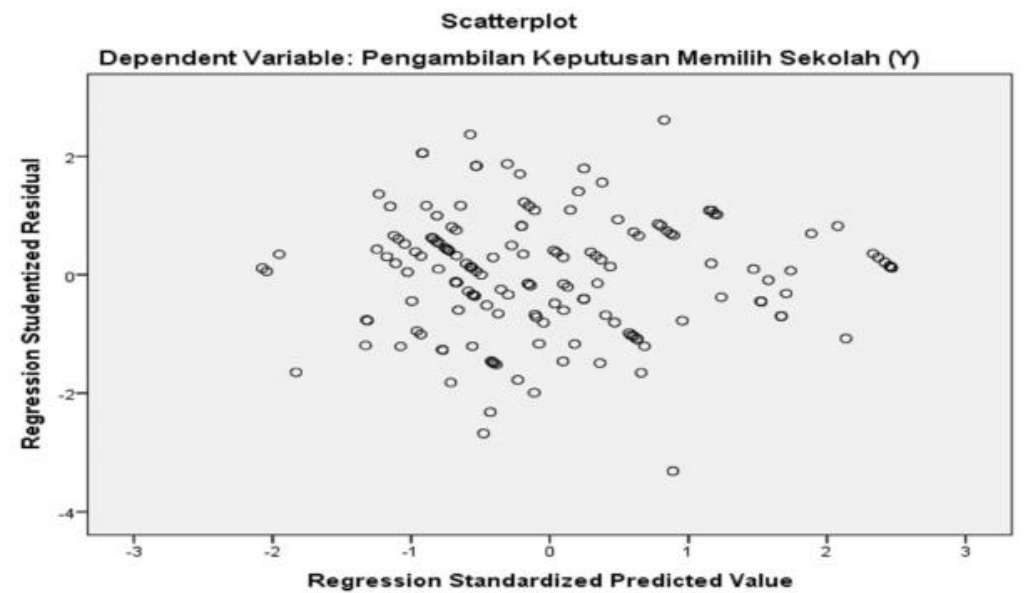

Grafik 2. Grafik Scatter Plot

Uji multikolinearitas bertujuan untuk menguji apakah model regresi ditemukan adanya korelasi antar variabel bebas (independen). Model regresi yang baik seharusnya tidak terjadi korelasi diantara variabel (Ghozali, 2011). Pada bagian coeficient terlihat untuk kelima variable independent, angka VIF ada di bawah angka 10 ( $\mathrm{X}_{1}$ misal 1.962). Demikian juga nilai tolerance dibawah angka 1 (seperti untuk variabel $\mathrm{X}_{1}$ adalah 0,510). Dengan demikian dapat disimpulkan model regresi tersebut tidak terdapat multikolinieritas antar variabel bebas dalam model regresi.

Tabel 1. Koefisien Uji Multikolinearitas

Coefficients*

\begin{tabular}{|c|c|c|c|c|c|c|c|c|}
\hline & \multirow{2}{*}{ Model } & \multicolumn{2}{|c|}{$\begin{array}{l}\text { Unstandardized } \\
\text { Coefficients }\end{array}$} & \multirow{2}{*}{$\begin{array}{c}\begin{array}{c}\text { Standardized } \\
\text { Coefficients }\end{array} \\
\text { Beta }\end{array}$} & \multirow{2}{*}{$\mathrm{t}$} & \multirow{2}{*}{ Sig. } & \multicolumn{2}{|c|}{$\begin{array}{l}\text { Collinearity } \\
\text { Statistics }\end{array}$} \\
\hline & & B & $\begin{array}{l}\text { Std. } \\
\text { Error }\end{array}$ & & & & Tolerance & VIF \\
\hline \multirow{6}{*}{1} & (Constant) & ,492 & 2,141 & & ,230 &, 818 & & \\
\hline & Fasilitas Sekolah (X1) &, 020 & 049 &, 024 & ,413 & ,680 &, 510 & 1,962 \\
\hline & Budaya Sekolah (X2) & ,145 &, 054 & , 164 & 2,670 &, 008 & ,443 & 2,257 \\
\hline & Lokasi Sekolah (X3) & ,489 &, 051 & ,563 & 9,534 &, 000 & ,477 & 2,096 \\
\hline & Religiusitas (X4) &, 011 &, 041 & ,013 & ,267 & ,790 & ,663 & 1,509 \\
\hline & Kepuasan Pelanggan (X5) &, 231 &, 046 & ,256 & 5,043 &, 000 & 648 & 1,544 \\
\hline
\end{tabular}

${ }^{*}$ Dependent Variable: Pengambilan Keputusan Memilih Sekolah (Y)

Uji autokorelasi, salah satu syarat yang harus dipenuhi oleh model regresi adalah tidak ada autokorelasi. Berdasarkan hasil pengujian autokorelasi me-nunjukkan bahwa nilai Durbin Watson sebesar 1,716 di mana angka tersebut terletak di antara -2 dan +2 yang berarti tidak ada autokorelasi dalam model regresi yang digunakan. Dengan demikian, asumsi-asumsi normalitas, heteroskedastisitas, multikolinearitas dan autokorelasi dalam model regresi dapat dipenuhi dari model ini. 
Tabel 2. Koefisien Durbin-Watson

\begin{tabular}{cc}
\multicolumn{2}{c}{ Model Summary $^{\mathrm{b}}$} \\
\hline Model & Durbin-Watson \\
\hline 1 & $1,716^{\mathrm{a}}$ \\
\hline
\end{tabular}

a. Predictors: (Constant), Kepuasan Pelanggan $\left(\mathrm{X}_{5}\right)$, Fasilitas Sekolah $\left(\mathrm{X}_{1}\right)$, Religiusitas $\left(\mathrm{X}_{4}\right)$, Lokasi Sekolah $\left(\mathrm{X}_{3}\right)$, Budaya Sekolah $\left(\mathrm{X}_{2}\right)$

b. Dependent Variable: Pengambilan Keputusan Memilih Sekolah (Y)

Dalam upaya menjawab permasalahan dalam penelitian ini maka digunakan analisis regresi linear berganda (Multiple Regression) dengan metode stepwise. Model regresinya adalah:

$$
\mathrm{Y}=\mathrm{a}+\mathrm{b}_{1} \mathrm{X}_{1}+\mathrm{b}_{2} \mathrm{X}_{2}+\mathrm{b}_{3} \mathrm{X}_{3}+\mathrm{b}_{4} \mathrm{X}_{4}+\mathrm{b}_{5} \mathrm{X}_{5}+e
$$

Keterangan:

$$
\begin{aligned}
\mathrm{Y} & =\text { pengambilan keputusan memilih sekolah } \\
\mathrm{a} & =\text { constanta } \\
\mathrm{b}_{1}= & \text { Koefisien regresi antara fasilitas sekolah dengan pengambilan keputusan memilih } \\
& \text { sekolah } \\
\mathrm{b}_{2} \quad= & \text { Koefisien regresi antara budaya sekolah dengan pengambilan keputusan memilih } \\
& \text { sekolah } \\
\mathrm{b}_{3}= & \text { Koefisien regresi antara lokasi sekolah dengan pengambilan keputusan memilih } \\
& \text { sekolah } \\
\mathrm{b}_{4}= & \text { Koefisien regresi antara religiusitas dengan pengambilan keputusan memilih } \\
& \text { sekolah } \\
\mathrm{b}_{5}= & \text { Koefisien regresi antara kepuasan pelanggan dengan pengambilan keputusan } \\
& \text { memilih sekolah } \\
\mathrm{X}_{1}= & \text { Variabel fasilitas sekolah } \\
\mathrm{X}_{2}= & \text { Variabel budaya sekolah } \\
\mathrm{X}_{3}= & \text { Variabel lokasi sekolah } \\
\mathrm{X}_{4}= & \text { Variabel religiusitas } \\
\mathrm{X}_{5}= & \text { Variabel kepuasan pelanggan } \\
\mathrm{e}= & \text { error disturbances }
\end{aligned}
$$

Hasil dari analisis regresi dengan metode stepwise memberikan rekomendasi agar variabel fasilitas sekolah dan religiusitas dikeluarkan dari model karena tidak signifikan memberikan pengaruh kepada pengambilan keputusan memilih sekolah. Begitu juga dengan nilai konstanta regresi. Oleh karena itu dilakukan regresi ulang tanpa melibatkan konstanta, variabel fasilitas sekolah dan variabel religiusitas. Hasil analisis regresi dapat dilihat pada Tabel 3. Dengan demikian model regresi yang terbentuk adalah :

$$
Y=0,499 X_{3}+0,231 X_{5}+0,158 X_{2}
$$


Tabel 3. Hasil Analisis Regresi Stepwise

\section{Coefficients*)}

\begin{tabular}{|c|c|c|c|c|c|c|}
\hline & \multirow[t]{2}{*}{ Model } & \multicolumn{2}{|c|}{$\begin{array}{l}\text { Unstandardized } \\
\text { Coefficients }\end{array}$} & \multirow{2}{*}{$\begin{array}{c}\text { Standardized } \\
\text { Coefficients } \\
\text { Beta }\end{array}$} & \multirow[t]{2}{*}{$\mathrm{t}$} & \multirow[t]{2}{*}{ Sig. } \\
\hline & & $\mathrm{B}$ & Std. Error & & & \\
\hline \multirow{3}{*}{1} & (Constant) & 9,036 & 1,666 & & 5,424 &, 000 \\
\hline & Lokasi Sekolah (X3) &, 709 &, 041 & 818 & 17,506 &, 000 \\
\hline & (Constant) & 3,769 & 1,731 & & 2,177 &, 031 \\
\hline \multirow[t]{3}{*}{2} & Lokasi Sekolah (X3) & ,568 &, 043 & 655 & 13,130 &, 000 \\
\hline & Kepuasan Pelanggan (X5) & 273 & ,045 & ,303 & 6,073 &, 000 \\
\hline & (Constant) & ,893 & 1,869 & & ,478 & ,634 \\
\hline \multirow{3}{*}{3} & Lokasi Sekolah (X3) & ,499 &, 046 &, 575 & 10,763 &, 000 \\
\hline & Kepuasan Pelanggan (X5) & ,231 &, 045 &, 256 & 5,107 &, 000 \\
\hline & Budaya Sekolah (X2) &, 158 & 046 &, 179 & 3,442 & ,001 \\
\hline
\end{tabular}

${ }^{*}$ Dependent Variable: Pengambilan Keputusan Memilih Sekolah (Y)

Pada Tabel 4 diperoleh nilai R2 $=0,753$. Artinya variabel independen (lokasi sekolah, kepuasan pelanggan, dan budaya sekolah) dapat menerangkan variabilitas sebesar 75,3 persen dari variabel dependen (pengambilan keputusan memilih sekolah), sedangkan sisanya diterangkan oleh variabel lain. Sementara dari Tabel 5 , dapat dilihat uji $F$ yang nilainya signifikan $(<0,05)$ sehingga model secara keseluruhan dapat dianggap bagus.

Tabel 4. Koefisien Determinasi

Model Summary

\begin{tabular}{ccccc}
\hline Model & $\mathrm{R}$ & R Square & $\begin{array}{c}\text { Adjusted R } \\
\text { Square }\end{array}$ & $\begin{array}{c}\text { Std. Error of the } \\
\text { Estimate }\end{array}$ \\
\hline 1 &, $818^{\mathrm{a}}$ &, 668 &, 666 & 2,63608 \\
2 &, $856^{\mathrm{b}}$ &, 734 &, 730 & 2,37101 \\
3 &, $868^{\mathrm{c}}$ &, 753 &, 748 & 2,29018 \\
\hline
\end{tabular}

a. Predictors: (Constant), Lokasi Sekolah $\left(\mathrm{X}_{3}\right)$

b. Predictors: (Constant), Lokasi Sekolah $\left(\mathrm{X}_{3}\right)$, Kepuasan Pelanggan $\left(\mathrm{X}_{5}\right)$

c. Predictors: (Constant), Lokasi Sekolah (X3), Kepuasan Pelanggan $\left(\mathrm{X}_{5}\right)$, Budaya Sekolah $\left(\mathrm{X}_{2}\right)$

Tabel 5. Analisis Varian

ANOVA $^{a}$

\begin{tabular}{|c|c|c|c|c|c|c|}
\hline \multicolumn{2}{|c|}{ Model } & \multirow{2}{*}{$\frac{\text { Sum of Squares }}{2129,534}$} & \multirow{2}{*}{$\frac{\mathrm{df}}{1}$} & \multirow{2}{*}{$\begin{array}{r}\text { Mean Square } \\
2129,534\end{array}$} & \multirow{2}{*}{$\frac{F}{306,456}$} & \multirow{2}{*}{$\begin{array}{l}\text { Sig. } \\
, 000^{\mathrm{b}}\end{array}$} \\
\hline & Regression & & & & & \\
\hline \multirow[t]{3}{*}{1} & Residual & 1056,233 & 152 & 6,949 & & \\
\hline & Total & 3185,766 & 153 & & & \\
\hline & Regression & 2336,892 & 2 & 1168,446 & 207,846 &, $000^{\mathrm{c}}$ \\
\hline \multirow[t]{3}{*}{2} & Residual & 848,874 & 151 & 5,622 & & \\
\hline & Total & 3185,766 & 153 & & & \\
\hline & Regression & 2399,027 & 3 & 799,676 & 152,466 &, $000^{\mathrm{d}}$ \\
\hline \multirow[t]{2}{*}{3} & Residual & 786,739 & 150 & 5,245 & & \\
\hline & Total & 3185,766 & 153 & & & \\
\hline
\end{tabular}




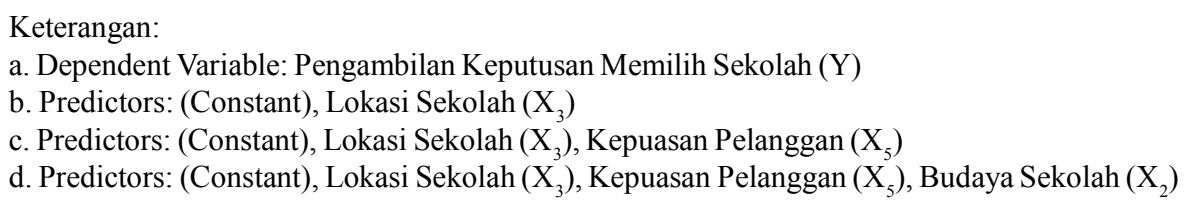

Hasil analisis data menunjukkan bahwa dua variabel dari pengambilan keputusan memilih sekolah yaitu dimensi fasilitas sekolah dan religiusitas dianggap tidak berpengaruh terhadap pengambilan keputusan memilih sekolah. Hal ini bisa disebabkan karena sudah jelas terlihat bahwa gedungnya besar berarti fasilitasnya pasti bagus. Dapat juga disebabkan karena para orang tua merasa sekolah tersebut adalah sekolah yang paling dekat dengan tempat tinggalnya sehingga untuk mencari kemudahannya, para orang tua memasukkan ke sekolah tersebut, atau sebab-sebab lainnya. Sedangkan untuk religiusitas bisa dintrepretasikan bahwa orang tua siswa tidak mempertimbangkan keputusan mereka dari segi religiusitas karena sudah menjadi tradisi dalam keluarga yang agamis di rumah atau lingkungannya bahwa anak-anak mereka harus masuk ke sekolah tersebut. Karena SD Virgo Maria 2 dan SDIP. H. Soebandi dikelola oleh yayasan yang juga memiliki taman kanakkanak (TK) maka banyak siswa baru yang berasal dari TK di yayasan tersebut berlanjut ke SD sehingga para orang tua sudah tidak mempertimbangkan masalah religiusitas, atau sebab-sebab lainnya.

Terdapat berbagai faktor yang mempengaruhi pengambilan keputusan orang tua dalam memilih sekolah, maka variabel lokasi sekolah, kepuasan pelanggan dan budaya sekolah adalah sebagian dari faktor-faktor tersebut. Faktor paling dominan adalah lokasi sekolah yaitu sebesar 66,8 persen, apabila diambil 2 faktor yang dominan yaitu lokasi sekolah dan kepuasan pelanggan maka akan memberikan pengaruh sebesar 73,0 persen, dan apabila diambil 3 faktor yang dominan yaitu lokasi sekolah, kepuasan pelanggan dan budaya sekolah maka akan memberikan pengaruh sebesar 74,8 persen. Hal ini menunjukkan adanya ketiga variabel bebas tersebut secara bersamaan, memberikan dampak positif yang lebih besar dibanding secara individu. Jadi orang tua dalam mengambil keputusan memilih sekolah tidak hanya memperhatikan lokasi sekolah saja, atau berdasar pada kepuasan pelanggan semata, atau memperhatikan budaya sekolah secara parsial. Namun ketiga hal tersebut diperhatikan secara bersama-sama.

\section{P E N U T U P}

Dari keseluruhan pembahasan yang telah dipaparkan pada bab terdahulu mengenai faktorfaktor yang berpengaruh terhadap pengambilan keputusan orang tua siswa dalam memilih sekolah di SD Virgo Maria 2 dan SDIP H. Soebandi Kecamatan Bawen Kabupaten Semarang dapat disimpulkan bahwa faktor lokasi sekolah, kepuasan pelanggan dan budaya sekolah berpengaruh positif dan signifikan sebesar terhadap pengambilan keputusan orang tua dalam memilih sekolah di SD Virgo Maria 2 dan SDIP. H. Soebandi Kecamatan Bawen Kabupaten Semarang; dan faktor yang dominan mempengaruhi pengambilan keputusan orang tua dalam memilih sekolah di SD Virgo Maria 2 dan SDIP. H. Soebandi Kecamatan Bawen Kabupaten Semarang antara lain lokasi sekolah berpengaruh sebesar 66,8 persen.

Hasil penelitian ini menunjukkan bahwa ada pengaruh positif dan signifikan antara lokasi sekolah terhadap pengambilan keputusan orang tua dalam memilih sekolah bagi putra-putrinya. Hal ini sejalan dengan hasil penelitian Bosetti (2004), Adryana (2009), dan Lai, Sadoulet dan Janvry (2007). Hasil penelitian ini menunjukkan bahwa ada pengaruh positif dan signifikan antara kepuasan pelanggan dan budaya sekolah terhadap pengambilan keputusan orang tua dalam memilih sekolah 
bagi putra-putrinya. Hal ini sejalan dengan hasil penelitian Hadikusumo (2012).

Lokasi sekolah memberi pengaruh positif dan signifikan yang paling besar terhadap pengambilan keputusan orang tua dalam memilih sekolah terutama lingkungan sekolah yang baik, maka untuk menarik perhatian para orang tua, hendaknya sekolah dan masyarakat sekitar dapat menciptakan dan meningkatkan keamanan dan kenyamanan di lingkungan sekolah. Kepuasan pelanggan memberi pengaruh positif dan signifikan terhadap pengambilan keputusan orang tua dalam memilih sekolah, maka sekolah perlu untuk meningkatkan dan mempertahankan pres-tasi anak dan sekolah baik di bidang akademik maupun non akademik sehingga para orang tua dan siswa sebagai pelanggan akan merasa puas pada hasil yang dicapai dan tetap setia memasukkan putra-putrinya ke sekolah tersebut. Budaya sekolah memberi pengaruh positif dan signifikan terhadap pengambilan keputusan orang tua dalam memilih sekolah, maka untuk menarik minat para orang tua, seluruh warga sekolah perlu untuk meningkatkan dan mempertahankan kualitas sekolah baik di bidang akademik maupun non akademik.

\section{DAFTAR PUSTAKA}

Adryana, Septi. 2009. Analisa Faktor-Faktor Yang Mempengaruhi Pemilihan Sekolah Dasar Di Kota Depok Menggunakan Metode Proses Analisa Bertingkat. Jurnal Basis Data, ICT Research Center UNAS. ISSN 1978-9483 Vol.4 No.1 Mei 2009. (www.unas.ac.id) diunduh tanggal 14 Maret 2012

Arianto, Sam. 2008. Pengertian Fasilitas Belajar,(On line), (http://sobatbaru.blogspot.com/2008) diakses 28 Desember 2010.

Arikunto, Suharsimi. 2010. Prosedur Penelitian Suatu Pendekatan Praktek. Jakarta: Rineka Cipta.

Bosetti, Lynn. 2004. Determinantsof school choice: Understanding How Parents Choose Elementary Schools in Alberta. Journal of Education Policy Vol. 19, No. 4. Kanada: Taylor \& Francis Ltd

Ghozali, Imam. 2011. Aplikasi Analisis Multivariate Dengan Program IBM SPSS 19. Semarang: Badan Penerbit Universitas Diponegoro.

Hadikusumo, Kunaryo. 2012. Faktor-Faktor yang Berpengaruh Terhadap Pengambilan Keputusan Orang Tua Siswa Dalam Memilih Sekolah di SDIAl-Azhar 14 Semarang. Disertasi. Semarang: Universitas Negeri Semarang.

Kirkland, David E. 2010. Choices We Can Believe In: City Parents And School Choice. Journal of Equity in Education. Vol 1 Issue 1 Winter 2010

Koentjaraningrat. 1990. Pengantar Ilmu Antropologi. Jakarta: Rineka Cipta.

Lai, Sadoulet, dan Janvry, 2007. Can Parents Make Well-Informed School Choices?. (http:// socrates.berkeley. edu/ raphael/IGERT/Workshop/schoolchoice_info_paper083107.pdf) diunduh tanggal 14 Maret 2012

Mangunwijaya, Y.B. 1986. Menumbuhkan Sikap Religiusitas Anak. Jakarta: Gramedia

Rehman, Khan, Tariq, dan Tasleem. 2010. Determinants of Parents' Choice in Selection of Private Schools for their Children in District Peshawar of Khyber Pakhtunkhwa Province. European Journal of Scientific Research. ISSN 1450-216X Vol.44 No.1 (2010), pp.140-151. (http:/ www.eurojournals.com) diunduh tanggal 16 Maret 2012. 
Sugiyono. 2002. Metode Penelitian Administrasi. Bandung: Alfabeta.

Supranto, Johanes. 1998. Teknik Pengambilan Keputusan. Jakarta: PT Rineka Cipta.

Surya, M. 1979. Psikologi Pendidikan. Bandung: Jurusan PPB FIP IKIP.

Tarigan, R. 2006. Perencanaan Pembangunan Wilayah. Edisi Revisi, Bumi Aksara, Jakarta.

Waryanto, Budi dan Millafati, Astika. 2006. Transformasi Data Skala Ordinal Ke Interval Dengan Menggunakan Makro Minitab. Jurnal Informatika Pertanian Vol 15, 2006 hal 881-895. (www.litbang.deptan.go.id). Diunduh tanggal 07 Pebruari 2013. 